\title{
Study on the Health Benefits of Brown Algae (Sargassum muticum) in Volunteers
}

\author{
Shin Young Park ${ }^{1}$, Inn Su Seo ${ }^{2}$, Sun Joo Lee ${ }^{3}$, Sang Pyung Lee ${ }^{4, *}$ \\ ${ }^{1}$ Department of Clinical Pathology, Cheju Halla University, Jeju 690-708, Korea \\ ${ }^{2}$ Bio Convergence center, Jeju Technopark, Jeju 690-756, Korea \\ ${ }^{3}$ Department of Chemisty, Jeju National University, Jeju 690-756, Korea \\ ${ }^{4}$ Neuroscience Center, Cheju Halla Hospital, Jeju 690-170, Korea \\ *Corresponding author: nsdr745@gmail.com
}

Received January 22, 2015; Revised February 09, 2015; Accepted February 27, 2015

\begin{abstract}
A randomized clinical trial enrolling healthy volunteers was carried out to evaluate the effects of $S$. muticum supplementation. An experiment was conducted to investigate whether intake of $S$. muticum could exert beneficial effects on human health. Volunteers were asked to consume dried encapsulated S. muticum 4.8 grams daily for 4 weeks. Analysis was made on several parameters including blood lipid profile, stress hormone level, fatigue status, liver functions, and lymphocyte subpopulation level, before and after consumption of the S. muticum capsuls. Fifty-one subjects were able to complete this study. Oxidized LDL (ox-LDL) decreased $14 \%$ from the baseline level of $6.0 \pm 1.4 \mu \mathrm{g} / \mathrm{mL}$ to $5.1 \pm 1.6 \mu \mathrm{g} / \mathrm{mL}$, and the difference was statistically significant $(\mathrm{p}<0.05)$. There was a correlation between decreased ox-LDL levels and increased total antioxidant status (TAS) levels after $S$. muticum intake. There was a remarkable increase in natural killer (NK) lymphocyte count, but changes in the mean absolute lymphocyte subsets were unremarkable. Healthy subjects showed significant improvement of biomarkers of fatigue and liver functions, such lactate dehydrogenase (LDH), aspartate aminotransferase (AST), and alanine aminotransferase (ALT). These results suggest that $S$. muticum may have potential beneficial effects as a healthy food supplement through its antioxidant, hepatoprotective and immunologic functions.
\end{abstract}

Keywords: seaweed, antioxidant, hepatoprotection, food supplement, natural killer lymphocyte

Cite This Article: Shin Young Park, Inn Su Seo, Sun Joo Lee, and Sang Pyung Lee, "Study on the Health Benefits of Brown Algae (Sargassum muticum) in Volunteers." Journal of Food and Nutrition Research, vol. 3, no. 2 (2015): 126-130. doi: 10.12691/jfnr-3-2-9.

\section{Introduction}

There are about 6,000 seaweed species in the world. They are classified into three major groups: green (chlorophytes), red (rhodophytes) and brown (phaeophytes). Brown seaweeds are the group with the largest production, contributing approximately to $59 \%$ of the total production in 2006, followed by red (40\%) and green $(<1 \%)$ seaweeds [1]. Brown seaweed especially contains many types of bioactive compounds such as omega-3 polyunsaturated fatty acids, polyphenols, polysaccharides, fucosterol, and fucoxantin. These bioactive compounds are used as the source of foods, animal feeds and medicine. Algal polyphenols have many biological activities, including anti-inflammatory, hepatoprotective, anti-tumor, and anti-hypertensive, as well as anti-diabetic activity based on the inhibition of $\alpha$ glucosidase [2].

Sargassum muticum (Yendo), a species of brown algae called "Mojaban" has been a favorite food for years as it is used for preparing "Mom-guk" soup, a well-known traditional seafood broth of Jeju Island, South Korea. "Mom-guk" is blessed with the abundance of various minerals, vitamins and dietary fibers. Brown algae are increasingly on the focus as a natural healthy diet. According to our knowledge, no study has been conducted in humans to investigate the medicinal benefits of ( $S$. muticum) with antioxidant, anti-inflammatory, hepatoprotective, anticancer and cholesterol-lowering effects until now.

Findings of in vitro studies indicated that Sargassum sp. had biological functions of the natural marine harvest, which included anti-tumor, antioxidant, anti-bacterial, anti-fungal, anti-inflammatory, and anti-viral activities $[3,4]$. Recently, cardiovascular disease, malignancy and other chronic illnesses are the most frequent cause of death. They all share a multifactorial origin and are caused by complex interactions between genetic predisposition and personal life style [5]. It seems important to rectify a poorly-balanced nutritional condition of dietary habits to prevent life-style related diseases, such as metabolic syndrome. More recently, food industry, agricultural community and now the consumers have all shown a growing interest in the field of functional foods. Brown algae is a rich source of structurally-novel and biologically active metabolites [6]. Primary or secondary metabolites produced by brown algae may potentially be bioactive compounds of interest in food and nutraceutical industries. 
Researchers are focusing on many functional ingredients in foods which may be useful for the prevention and treatment of life-style-related diseases. Among them, brown algae are such ingredient. Polyphenols have emerged as one major category of natural products important to human health. Increasing scientific evidence shows that polyphenols are a good antioxidant and effective in preventing cardiovascular and inflammatory diseases. They may also be used as a chemo-preventative agent for cancer [7]. Phlorotannins (brown-algal polyphenols), a subgroup of tannins, are the least studied group of tannins and are found only in brown algae. They are produced entirely by polymerization of phloroglucinol $[8,9]$. Moreover, brown algae have been recognized as potential sources of these compounds [10]. Many studies have investigated brown algae, such as Undaria pinnatifida (Wakame), Hijikia fusiformis (Hijiki), Laminaria japonica (Ma-Kombu), and Sargassum fulvellum [11,12]. However, the data on S. muticum, except in anti-inflammatory properties, $[13,14]$ are to our knowledge not available. Until now, no studies have been performed in humans to determine the medicinal benefits of S. muticum including antioxidant, anti-inflammatory, hepatoprotective, antitumor, and cholesterol-lowering effects. Thus, this randomized clinical trial enrolling healthy volunteers was conducted to evaluate the effects of $S$. muticum supplementation.

The aim of this study was to investigate whether moderate intake of $S$. muticum could exert beneficial effects on human health. Volunteer subjects were mostly nurses having a known stressful occupation. They were asked to consume dried encapsulated $S$. muticum daily for 4 weeks. Then, analysis was made on several parameters which included lipid profile, stress hormone level, fatigue status, liver functions and lymphocyte subpopulation level.

\section{Materials and Methods}

\subsection{Participants}

This study enrolled 51 healthy volunteers from a hospital in Jeju Island, who satisfied the inclusion criteria. The inclusion criteria comprised: 1) men and women ages from 20 to 55 years, 2) having no known chronic diseases, 3) who are not currently using any medication, and 4) have no known allergy or hypersensitivity to any food or material. The characteristics of 51 voluntary subjects enrolled in the study are listed in Table 1.

The participants were informed of the purpose and risks of the study, and a written informed consent was obtained from each participant. The study protocol was approved by the Institutional Review Board of the Hospital District of Jeju (Jeju City, Jeju Province), prior to the initiation of the study.

\subsection{Procedure}

The freeze-dried S. muticum was identified, powdered and encapsulated for easy consumption before these products were donated by the Jeju Biodiversity Research Institute(Jeju Biodiversity Research Institute, Seogwipo City, Jeju, South Korea). Each capsule contained 2.4 grams of powered $S$. muticum and all participants were instructed to take two of these capsules a day.
During the study period of four weeks, all participants maintained their usual dietary habits and no additional dietary supplements were allowed throughout the study. The body weight and height of all participants were measured and the body mass index (BMI) was calculated as the body weight $(\mathrm{kg})$ divided by the square of his or her height $\left(\mathrm{m}^{2}\right)$.

\subsection{Blood Collection and Analysis}

The fasting blood was collected at their screening visit (baseline) between 7 and 8 o'clock in the morning and at their final visit at the end of four weeks of this study. The blood samples $(10 \mathrm{~mL})$ were analyzed by separating the whole blood for lymphocytes and pyruvate; the plasma for oxidized LDL (ox-LDL), total antioxidant status (TAS), and lactate; the serum for lipid, aspartate aminotransferase (AST), alanine aminotransferase (ALT), lactate dehydrogenase (LDH), and cortisol. The whole blood in 8\% perchloric acid for pyruvate, the plasma in NaF tube for lactate, the serum in the SST tubes for AST, ALT, $\mathrm{LDH}$, and the lipid profiles were sent to the Green Cross Reference Lab. for blood analyses. The plasma concentrations of ox-LDL and serum TAS were measured in duplicates with ELISA kits (Cell Biolabs Inc, USA) according to the manufacturer's protocol (STA-388 and STA-360, respectively).

The flow cytometry analysis for lymphocyte subsets were carried out with the whole blood, which had been collected by using the EDTA vacutainer tubes on a FACS caliber Flow Cytometer (Becton Dickinson, USA). A single-platform assay using a lyse/no-wash procedure was performed with the Becton Dickinson (BD) tubes using the two-color direct immunofluorescence reagent kit (BD Simultest TM IMK Lymphocyte). The stained blood samples were lysed with a diluted lysing solution, and special care was taken not to expose the stained samples to light. $\mathrm{CD}^{+}{ }^{\mathrm{T}}$ cells, $\mathrm{CD}^{+}, \mathrm{CD}^{+}{ }^{+} \mathrm{T}$ helper cells, and $\mathrm{CD}^{+}$, $\mathrm{CD}^{+} \mathrm{T}$ cytotoxic cells were identified according to published protocols. The B cells and natural killer (NK) cells were also identified by the protocols.

\subsection{Statistical Analysis}

Microsoft Excel 2010 (Microsoft, Redmond, Washington, USA) was used for data entry, validation, and restructuring, as well as for calculating changes in variables over time, reorganizing/reformatting results and graphical preparation. The SPSS Base System ver. 19 (IBM SPSS, Chicago, IL, USA) was used for the comparisons of variables at the baseline $(\mathrm{T}=0)$ and at four weeks $(\mathrm{T}=28)$ of this study. A $p$-value of less than 0.05 was considered statistically significant (two-sided test).

\section{Results}

Of these 51 subjects, 2 discontinued this study for personal reasons. No adverse reactions (e.g., fever, hot flush, nausea, vomiting or diarrhea) were observed after the intake of $S$. muticum supplementation in 49 subjects who completed this study. Table 1 shows the demographics of 49 participants. The average BMI of participants was $22.5 \pm 3.1$ with normal standard weight. 
Table 1. General characteristics of participants $(n=49)$

\begin{tabular}{ll}
\hline Variables & Subjects $(\mathrm{n}=49)$ \\
\hline Age (mean) & $33 \pm 8.7$ years \\
Female/Male & $46 / 3$ \\
BMI $\left(\mathrm{kg} / \mathrm{m}^{2}\right)<25$ (Standard Weight) & $22.5 \pm 3.1$ \\
\hline Abbreviation: BMI, body mass index \\
$\quad$ The serum levels of total cholesterol (T-cho), \\
triglyceride (TG), LDL, HDL cholesterol, and plasma ox- \\
LDL were measured before ( $\mathrm{T}=0$ ) and after ( $\mathrm{T}=28) \mathrm{S}$. \\
muticum intake (Table 2).
\end{tabular}

Table 2. Effects of $S$. muticum supplementation on T-cho, TG, LDL, HDL and ox-LDL levels

\begin{tabular}{lllll}
\hline & Before & After & Diff $\dagger$ & Changes (\%) \\
\hline T-cho (mg/dL) & $186 \pm 26$ & $169 \pm 31$ & -17 & -9 \\
TG $(\mathrm{mg} / \mathrm{dL})$ & $65 \pm 32$ & $71 \pm 28$ & +6 & +9 \\
LDL $(\mathrm{mg} / \mathrm{dL})$ & $101 \pm 23$ & $94 \pm 34$ & -7 & -7 \\
HDL $(\mathrm{mg} / \mathrm{dL})$ & $64 \pm 10$ & $57 \pm 10$ & +7 & -10 \\
ox-LDL $(\mu \mathrm{g} / \mathrm{mL}) *$ & $6.0 \pm 1.4$ & $5.1 \pm 1.6$ & -0.9 & -14
\end{tabular}

Values expressed as the mean \pm standard deviation

*Significant differences, $p<0.001$

$\dagger$ Differences before and after treatment.

No significant differences were found, but a decreasing trend in the levels of T-cho and LDL cholesterol was observed. The level of ox-LDL decreased $14 \%$ from $6.0 \pm 1.4 \mu \mathrm{g} / \mathrm{mL}$ at the baseline to $5.1 \pm 1.6 \mu \mathrm{g} / \mathrm{mL}$ at four weeks into the study; the difference was statistically significant $(\mathrm{p}<0.001)$. A correlation between the decreased ox-LDL levels and increased TAS levels was found after the intake of $S$. muticum supplement. The TAS levels in most participants increased at 4 weeks compared to the baseline (Figure 1).

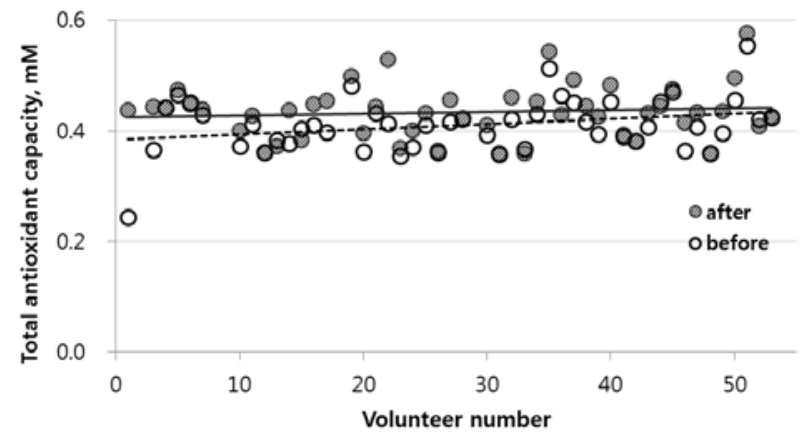

Figure 1. Changes of total antioxidant capacity before and after $S$. muticum intake

Table 3 shows the mean count of each absolute lymphocyte subset in the study population. No significant differences were noted except NK lymphocyte after $S$. muticum intake. However, an increasing trend in the absolute number of lymphocyte subsets from $4 \%$ to $9 \%$ was observed.

Table 3. The effects of $S$. muticum supplementation on the absolute number of lymphocyte subset $(n=49)^{a}$

\begin{tabular}{llll}
\hline Lymphocyte subsets & Before & After & Changes(\%) \\
\hline CD19 $^{+}$(B lymphocyte) & $249 \pm 104$ & $271 \pm 127$ & +9 \\
$\mathrm{CD}^{+}$(T lymphocyte) & $1551 \pm 491$ & $1650 \pm 482$ & +6 \\
$\mathrm{CD}^{+}$(helper T) & $840 \pm 291$ & $869 \pm 274$ & +4 \\
$\mathrm{CD}^{+}$(cytotoxic T) & $616 \pm 254$ & $669 \pm 268$ & +9 \\
$\mathrm{NK} \mathrm{lymphocyte}^{*}$ & $337 \pm 152$ & $379 \pm 120$ & +13 \\
$\mathrm{CD}^{+} / \mathrm{CD}^{+}$ & 1.36 & 1.29 & -4 \\
$\mathrm{NK}^{+} \mathrm{CD}^{+}$ & 0.40 & 0.44 & +8 \\
\hline
\end{tabular}

${ }^{\mathrm{a}}$ Absolute counts are given in cells per microliter.

Values are expressed as the mean \pm standard deviation.

*Significant differences, $p<0.05$
As shown in Table 3, NK lymphocytes significantly increased after 4 weeks of $S$. muticum intake. The mean $\mathrm{CD}^{+} / \mathrm{CD}^{+}$ratio decreased by $4 \%$ and the $\mathrm{NK} / \mathrm{CD} 4^{+}$ratio increased by $8 \%$ after $S$. muticum intake.

In order to investigate the mechanism underlying the antifatigue effect of $S$. muticum intake, the lactate and LDH concentrations were measured and analyzed for all participants $(n=49)$ and 3 different lactate levels, which were over $10 \mathrm{mg} / \mathrm{dL}$ at the beginning (Table 4).

Table 4. Effects of $S$. muticum supplementation on lactate and LDH concentrations

\begin{tabular}{ccccccc}
\hline & \multicolumn{2}{c}{ Lactate, mg/dL } & \multicolumn{4}{c}{ LDH, U/L } \\
\cline { 2 - 7 } & Before & After & $\begin{array}{c}\% \\
\text { Change }\end{array}$ & Before & After & $\begin{array}{c}\% \\
\text { Change }\end{array}$ \\
\hline total & $11.0 \pm 5.7$ & $9.70 \pm 3.0$ & $-17^{*}$ & $276 \pm 67$ & $277 \pm 58$ & 0 \\
$11 \sim 16$ & $15.7 \pm 6.1$ & $10.1 \pm 3.3$ & $-38^{*}$ & $285 \pm 53$ & $272 \pm 43$ & -4 \\
$17 \sim 20$ & $20.1 \pm 6.3$ & $11.0 \pm 3.6$ & $-45^{*}$ & $300 \pm 63$ & $266 \pm 51$ & -11 \\
over 20 & $30.1 \pm 2.2$ & $11.4 \pm 1.1$ & $-67^{*}$ & $338 \pm 87$ & $254 \pm 81$ & $-23^{*}$ \\
\hline
\end{tabular}

Values are expressed as the mean \pm standard deviation

* Significant differences, $p<0.01$

*Significant differences, $\mathrm{P}<0.001$

After S. muticum intake, the levels of lactate and $\mathrm{LDH}$ changed from $11.0 \pm 5.7$ to $9.7 \pm 3.0 \mathrm{mg} / \mathrm{dL}(\mathrm{p}<0.01)$ and $276 \pm 67$ to $277 \pm 58 \mathrm{U} / \mathrm{L}$, respectively. There were significant differences in 3 different lactate level subgroups after the intake of $S$. muticum. The 3 subgroups (11 16, 17 20 and over 20) showed a statistically significant decrease by $38 \%, 45 \%$ and $67 \%$ after $S$. muticum intake, respectively, (each component: $\mathrm{p}<0.01$ ). The LDH levels also decreased with increased lactate levels and showed the most significant decrease of $23 \%$ at the highest level of lactate, over 20 (Figure 2).

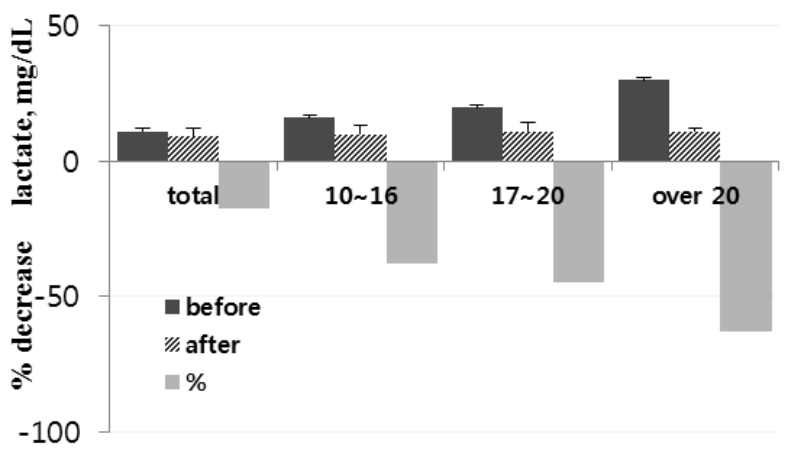

Figure 2. Changes in mean value of lactate before and after S. muticum intake: The lactate levels were compared with the total mean value of volunteers and 3 different mean values, which were 10-16, 17-20 and over 20

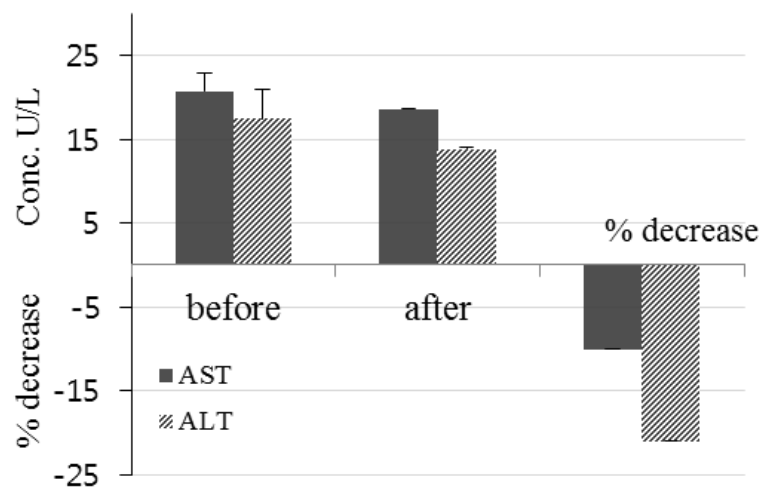

Figure 3. The effect of $\mathrm{S}$. muticum intake on AST an ALT levels, expressed as $\mathrm{U} / \mathrm{L} \pm$ standard deviation. ${ }^{*} \mathrm{p}<0.001$ as compared to T0 (paired T-test) 
Figure 2 shows the changes in mean value of lactate before and after $S$. muticum intake. The lactate levels were compared with the total mean value of volunteers and 3 different mean values, which were 10-16, 17-20 and over 20. A significant reduction by $21 \%$ was observed in ALT after $S$. muticum intake ( $\mathrm{p}<0.001)$. The decline was not so significant like that of ALT, but the AST levels also decreased by $10 \%$ after $S$. muticum intake (Figure 3 ).

\section{Discussion}

Bioactive compounds, such as meroterpenoids, phlorotannins, fucoidans, sterols and glycolipids, have been identified from Sargassum spp. These compounds include antibacterial, antifungal, anti-viral, antiinflammatory, anticoagulant, antioxidant, hypoglycaemic, hypolipidemic, antimelanogenic, anti-bone loss, and hepatoprotective and neuroprotective activities; which suggest that the genus Sargassum is a rich source of health maintaining and promoting agents [15]. S. muticum, a species of brown algae, has been used as the "foodstuff" of traditional seafood soup, "Mom-guk," in Jeju Island for a long time. People, who live in Jeju Island, say that "Mom-guk" is very healthy food, and especially good for liver protection.

This present study shows that 4-week supplementation of powered capsule $S$. muticum may give beneficial antifatigue, antistress and hepatoprotective effects to healthy volunteers by enhancing total antioxidant capacity and decreasing lactate and LDH, as well as AST and ALT.

Ox-LDL is one of the major causes of atherosclerosis, which is an inflammatory process involving soluble mediators, macrophages and vascular smooth muscle cells. Ox-LDL stimulates inflammatory signaling, trigger macrophages to accumulate cholesterol, and to form the foam cells of fatty streaks-the hallmark of early atherosclerotic lesions [16]. Since S. muticum intake showed increased TAS in most participants at 4 weeks compared to the baseline, it could potentially reduce the development of atherosclerotic lesions.

Polyphenols, as the second metabolites in vegetables, fruits, and medicinal plants, are popular chemo-preventive compounds attributing to the antioxidants and antiinflammatory properties [17]. A latest report from $S$. muticum study showed that apo-9'-fucoxanthinone, belonging to the norisoprenoid family, effectively suppressed lipopolysaccharide (LPS)-induced nitric oxide and prostaglandin E2 production [18]. Our results also supported the anti-inflammatory effect of S. muticum. An increasing trend in absolute number of lymphocyte subsets from $4 \%$ to $9 \%$ with a significant increase $(p<0.05)$ of NK lymphocyte by $13 \%$ was observed from the participants after the 4-week of $S$. muticum intake. It also altered the balance of $\mathrm{CD}^{+} / \mathrm{CD}^{+} \mathrm{T}$ cells by decreasing the ratio of $\mathrm{CD}^{+}$helper cells. These results can be related to the antioxidant and anti-fatigue effect by $S$. muticum intake. It was reported that restraint stress in mice changed the number of lymphocyte cells, altered antibodies production, and suppressed cytotoxicity of the NK and T cells. It also indicated that stress can impair immunocompetence via the oxidation process $[19,20]$. These results support our data by suggesting that the improved immunologic response was possibly due to the antioxidative capacity in the immune cells enhanced by $S$. muticum intake.
A study reported that the serum lactate concentration, as an index that measures the fatigue status, increased two folds or more after having stress or extensive exercise as compared to that after resting [21]. The result of this study showed that the lactate concentration significantly decreased after $S$. muticum intake; the lactate concentration of all subjects decreased substantially by $17 \%$ after $S$. muticum intake as compared with the concentration before the intake $(\mathrm{p}<0.001)$.

The result of analysis conducted by dividing participants into three groups by lactate concentration (11 16, 17 20, \& more than 20) showed that the group with a higher lactate concentration had a remarkable decrease in lactate concentration after $S$. muticum intake. In particular, it was suggested that $S$. muticum intake was very effective in lowering serum lactate concentration in the group with a high level of fatigue or in people with great stress. There were no differences in LDH levels before and after $S$. muticum intake for all subjects, but LDH levels significantly decreased as much as $23 \%$ in the group with high lactate concentration. Repeated acute stress applied to mice in a stress experiment increased activities of enzymes such as serum AST, ALT and LDH. Similarly, there were reports asserting that exposure to atmospheric pollutants also distinctively increased these enzymatic activities [22,23]. Thus, this study showed decreased levels of ALT and AST by $21 \%$ and $10 \%$, respectively, after $S$. muticum intake; such resultant decrease in enzymatic levels, especially of hepato-specific ALT, found in this study suggest that $S$. muticum has a liverprotective function. A significant reduction by $21 \%$ was observed in ALT after S. muticum intake $(\mathrm{p}<0.001)$. The decline was not so significant like that of ALT, but the AST levels also The heading of the Acknowledgment section and the References section must not be numbered.

\section{Conclusions}

Intake of S. muticum as a traditional foodstuff offsets the levels of biomarkers of stress and fatigue which suggest it has anti-stress and anti-fatigue effects.

\section{Acknowlegements}

This work was supported by Grant No. R0001028 from the Ministry of Trade, Industry \& Energy, Republic of Korea.

\section{References}

[1] D’Orazio, N., Gemello, E., Gammone, M.A., de Girolamo, M. Ficoneri, C. and Riccioni, G, "Fucoxantin: a treasure from the sea,” Mar. Drugs, 10. 604-616. 2012.

[2] Pallela, R., Na-Young, Y. and Kim, S.K, “Anti-photoaging and photoprotective compounds derived from marine organisms,” Mar. Drugs, 8. 1189-1202. 2010.

[3] Kim, J.Y., Lee, J.A., Kim, K.N., Yoon, W.J., Lee, W.J. and Park, S. Y, "Antioxidative and antimicrobial activities of Sargassum muticum extracts,” J. Korean Soc. Food Sci. Nutr. 36. 663-669. 2007.

[4] Mary, J.S., Vinotha, P. and Pradeep, A.M, “Screening for in vitro cytotoxic activity of seaweed, Sargassum sp. against Hep-2 and MCF-7 cancer cell lines,” Asian Pac. J. Cancer Prev. 13. 60736076. 2012 
[5] Hu, F.B., Liu, Y. and Willett, W.C, "Preventing chronic disease by promoting health diet and lifestyle: public policy implications for China,” Obes. Rev. 12. 552-559. 2011.

[6] Li, Y., Qian, Z.J., Ryu, B., Lee, S.H., Kim, M.M. and Kim, S.K, "Chemical components and its antioxidant properties in vitro: An edible marine brown alga, Ecklonia cava. Bioorg,” Med. Chem. 17. 1963-1973. 2009.

[7] Zhang, Q., Zang, J., Shen, J., Silva, A., Dennis, D.A. and Barrow, C.J, "A simple 96-well microplate method for estimation of total polyphenol content in seaweeds," J. Appl. Phycol. 18. 445-450. 2006.

[8] Koivikko, R., Loponen, J., Honkanen, T. and Jormalainen, V, "Contents of soluble, cell-wall-bound and exuded phlorotannins in the brown alga Fucus vesiculosus, with implications on their ecological functions,” J. Chem. Ecol. 31. 195-212. 2005.

[9] Kang, K.A., Lee, K.H., Park, J.W., Lee, N.H., Na, H.K., Surh, Y.J., You, H.J., Chung, M.H. and Hyun, J.W, "Triphlorethol-A induces heme oxygenase-1 via activation of ERK and NF-E2 related factor 2 transcrption factor,” FEBS Lett. 581. 2000-2008. 2007.

[10] Heo, S.J., Ko, S.C., Cha, S.H., Kang, D.H., Park, H.S., Choi, Y.U., Kim, D., Jung, W.K. and Jeon, Y.J, "Effect of phlorotannins isolated from Ecklonia cava on melanogenesis and their protective effect against photo-oxidative stress induced by UV-B radiation,' Toxicol In vitro, 23. 1123-1130. 2009.

[11] Ayyad, S.E., Ezmirly, S.T., Basaif, S.A., Alarif, W.M., Badria, A.F. and Badria, F.A, "Antioxidant, cytotoxic, antitumor, and protective DNA damage metabolites for the red sea brown alga Sargassum sp.,” Pharmacology Res. 3. 160-165. 2011.

[12] Yan, X., Chuda, Y., Suzuki, M. and Nagata, T, "Fucoxanthin as the major antioxidant in Hijikia fusiformis, a common edible seaweed," Biosci. Biotechnol. Biochem. 63. 605-607. 1999.

[13] Yoon, W.J., Ham, Y.M., Lee, W.J., Lee, N.H. and Hyun, C.G, "Brown alga Sargassum muticum inhibits proinflammatory cytokines, iNOS, and COX-2 expression in macrophage RAW 264.7 cells,” Turk. J. Biol. 34. 25-34. 2010.

[14] Yang, E.J., Ham, Y.M., Lee, W.J., Lee, N.H. and Hyun, C.G, "Anti-inflammatory effects of apo-9'-fucoxanthinone from the brown alga, Sargassum muticum,” Daru. 21. 62-68. 2013.

[15] Lie, L., Heinrich, M., Myers, S. and Dworjanyn, S.A, “Towards a better understanding of medicinal uses of the brown seaweed Sargassum in Traditional Chinese Medicine: a phytochemical and pharmacological review,” J. Ethnopharmacol. 142. 591-619. 2012

[16] Libby, P., Ridker, P.M. and Hansson, G.K, "Progress and challenges in translating the biology of atherosclerosis," Nature, 473, 317-325. 2011.

[17] D. Sliva, "Suppression of cancer invasiveness by dietary compounds,” Mini Rev. Med. Chem. 8. 677-688. 2008.

[18] Yang, E.J., Ham, Y.M., Lee, W.J., Lee, N.H. and Hyun, C.G, "Anti-inflammatory effects of apo-9'-fucoxanthinone from the brown alga, Sargassum muticum,” Daru, 21. 62-68. 2013.

[19] Kurihara, H., Koda, H., Asami, S., Kiso, Y. and Tanaka, T, "Contribution of the antioxidative property of astaxanthin to its protective effect on the promotion of cancer metastasis in mice treated with restraint stress,” Life Sci. 70. 2509-2520. 2001.

[20] He, R.R., Yao, X.S., Li, H.Y., Dai, Y., Duan, Y.H., Li, Y.F. and Kurihara, H, "The anti-stress effects of Sarcandra glabra extract on restraint-evoked immunocompromised,” Biol. Pharm. Bull. 32, 247-252. 2009.

[21] W. Shin, "The effect of convalescent meridian acupressure after exercise on stress hormones and lactic acid concentration change," J. Exerc. Rehabil. 9. 331-335. 2013.

[22] Devaki, M., Nirupama, R. abd Yajurvedi, H.N, "Repeated acute stress alters activity of serum aminotransferases and lactate dehydrogenase in rat,” JPBS, 23. 1-4. 2010.

[23] Abdou, H.M. and Hassan, M.A, "Protective role of omega-3 polyunsaturated fatty acid against lead acetate-induced toxicity in liver and kidney of female rats,” Biomed. Res. Int. 435857. 2014. 